Periodica Polytechnica Mechanical Engineering, 65(2), pp. 111-119, 2021

\title{
Estimation of Fatigue Longevity of Rod Elements of Complex Form
}

\author{
Leonid Berezin, Mykola Rubanka1', Alla Rubanka², Yurii Kovalov', Serhii Pleshko \\ ${ }^{1}$ Department of Applied Mechanics and Machines, Faculty of Mechatronics and Computer Technologies, Kyiv National University \\ of Technologies and Design, 01011 Kyiv, 2 Nemyrovycha-Danchenka Street, Ukraine \\ 2 Department of Ergonomics and Fashion Designing, Faculty of Design, Kyiv National University of Technologies and Design, \\ 01011 Kyiv, 2 Nemyrovycha-Danchenka Street, Ukraine \\ * Corresponding author, e-mail: berezin.Im@knutd.edu.ua
}

Received: 05 July 2019, Accepted: 15 January 2021, Published online: 16 March 2021

\begin{abstract}
The questions of design maintenance of a given fatigue longevity of rods of complex form during the intensification of load modes without changing of geometric, inertial and rigidity parameters of roads are considered. The study is conducted on the example of needles of circular machines with a small diameter of cylinder (automatic half-hose machines). An approach, based on the system of calculation of loads, loadings and resources under the criterion of fatigue strength, is proposed. The key link for the transition from the results of dynamic analysis to the determination of reliability indices is the dependence of limited longevity of needles on the cycles of load to fatigue failure with the use of statistical data on operating time to fatigue failure of the needles in production conditions. Since the random values of loads of the needles do not obey the normal law of distribution, the general description of density of distribution of amplitude of loads is presented. The influence of increase in speed parameters and constructive measures, aimed to reduce the corresponding loads at a current size of critical section of the needles, on the fatigue longevity is analyzed.
\end{abstract}

\section{Keywords}

designing, calculation, knitting needles, density of distribution, amplitude of load, cyclogram of loading, automatic half-hose machine

\section{Introduction}

The questions of longevity of rods of complex form on the example of knitting needles of circular machines of small diameter (automatic half-hose machines) are considered. The rods of the knitting needles have sections of a variable rectangular cross-section in length and a cylindrical hook in the zone of loop formation. Technological trajectories of the needles are given by a set of cams, which are called cams of knitting system. According to the results of the study of needle failures in production, the domination of hook destructions has been identified. Using the fractography analysis of surfaces of hook failures, the fatigue nature of destructions has been recorded [1, 2]. It is concluded that fatigue failures of needle hooks are the results of repeated action of repeated-variable loadings of the needle during the interaction with pitched cams that raise and lower the needles, and lateral cams, which braking needles on a given trajectory. The increase in stress in the critical section of the needle hook is also affected by the reflection of waves when changing the sections in the needle rod.
The needles belong to the parts that are criterial in size since the provision of required factors of safety by increasing the size in the critical section is impossible due to the technological requirements for the processing of yarn of certain tex. Therefore, the priority is given to analysis of the effect of needle loading on its fatigue longevity and to justification when choosing design solutions for cams of knitting systems and rational load modes. Since in the future the work of the automatic half-hose machines is close to continuous and without the involvement of service personnel, there are the requirements for the extension of the needles' life cycle. Besides, a reasonable assessment of their longevity also contributes to the development of rational consumption rates of the needles during operation and modes of maintenance of automatic half-hose machines.

\section{Literature review}

It should be noted that most publications on the reliability of machines are mathematically oriented mainly 
on parts and structures of general engineering [3, 4], represent innovations to ensure reliability [5], analyze the mechanics of damages and destructions [6] in constructions depending on the material [7], or cover a specific direction, for example [8,9]. In the paper [10], the types of the needles' failures are studied; the work [11] presents the ways to increase their useful lifetime. The purpose of the work aimed at determining the reasons for the needles' failures is primarily related to fractographic studies of fatigue fractures of the hooks [2] and the damage from wear [12]. Also, a set of organizational and technical measures to obtain complete and reliable information on a comprehensive study of the needles' failures is presented. It is found that fatigue failures of hooks prevail in automatic half-hose machines of the middle class, while failures from wearing prevail in high-class automatic half-hose machines that process synthetic threads. Also, attention was paid to the development of the systems of damage detection in production conditions. The approach that is based on machine vision and the technology of processing the images for the needles [13] and the loop structure [14] is considered as the modern one. The summary on operational and bench tests of the needles is presented in [15], in accordance with the results of which the dominant type of destruction of the knitting needles in automatic half-hose machines of the middle 14 class is determined, the values of the intensities of their failures are given, and the main factors influencing the destruction are listed. The classification of the needles and cams of knitting machines is outlined in review work [16]; the modeling of the process of loop formation when the needles interact with the cams that have working areas on polynomial curves is provided in the research [17]; innovative trends in their design improvements are given in [18]; the current state is comprehensively presented at the world exhibitions of the textile industry ITMA [19].

However, most works are devoted to the dynamic analysis of the needles' interaction with pitched cams [20, 21], among which - the classical work [22], where the theoretical positions and experimental data are systematized to estimate the number of impact loads and determine the rational design parameters of the knitting systems. Taking this, the dynamic models are not enough to analyze the reliability of the needles, because there is no unified transition from the spectrum of variable loadings to the equivalent stresses in the needles at corresponding cycles of their endurance to failure.
Besides, the acceptability of existing provisions on calculations of fatigue longevity [23] of the needles is limited by many reasons, in particular: by the complexity of their forms; by the inability to ensure the required factors of safety in the critical section due to increase in size; by the complexity of calculation of the overall coefficient of reduction of the fatigue limit, which takes into account the design and technological features of the needles; by the lack of information on the parameters of fatigue of needles that meet the working conditions.

Given that the issues of the complex estimation of the longevity of the knitting needles (from the loads to the calculation of indicators) are not considered, the problem of ensuring the set level of their longevity at the design stage or during the planning of the residual resource in production is relevant. The aim of the article is to develop the algorithm for calculating the fatigue longevity of details of complex forms and without excess factors of safety on the example of knitting needles of the automatic half-hose machines, for which the application of the traditional approaches is limited.

\section{Research methodology}

The calculation of longevity for any detail at the design stage includes dynamic analysis for determination of load conditions, calculation of characteristics of loading and indicators of longevity. The key link that provides the implementation of calculation is the dependency of limit values of limited fatigue of detail $\bar{\sigma}_{R_{d} N_{i}}$ on its cycle longevity $N_{i}$, which is appropriate to present graphically in semi-logarithmic coordinates $\bar{\sigma}_{R_{d} N_{i}}-\lg N_{i}$.

The information for calculation of statistical estimates of operating time to fatigue failure of needle hooks $T_{i}$ at the first stage was obtained during test testing of needles at different levels of loading with the subsequent transition to cycle longevities $N_{i}$. Standard needles from different batches were examined at the experimental installation in order to average the influence of constructive and technological factors on the fatigue strength. The size of tests was determined by the parameters of log-normal distribution of service life till the failure of needles [24]. In order to prevent the impact of landing of needles into the cylinder, they were installed with a production bend of the rod. Within each series of tests, the constancy of the given circle speed was maintained $\left(V_{x_{i}}=0.9 ; 1.0 ; 1.2 \mathrm{~m} / \mathrm{s}\right.$ ), and the cylinder of the machine was filled with a batch of new needles. The pitch angles of working surfaces of cams that raise and lower the needles at the installation were $\alpha=45^{\circ}$. 
The transition to cycle longevity for each level of load was performed using the formula:

$N_{i}=60 T_{i} n s$,

where $n$ - the rate of rotation of needle cylinder stand; $s=6-$ number of needle interactions with cams per one cylinder rotation (three pairs of cams for raising and lowering the needles).

As a result of calculations, at circular speeds of cylinder $V_{x_{i}}$, the corresponding values of cycles

$\bar{N}_{i}=(8.32 ; 4.79 ; 3.16) \times 10^{7}$ were obtained, which corresponded to the probability of failure $P=50 \%$ and set the mean quadratic deviation $S_{\lg N_{i}}=0.907$.

The loads of needles $y_{i}$ during the interaction with pitched cams were determined analytically at maximum values [15]:

$$
\begin{aligned}
& y_{\text {max }_{i}}=V_{x_{i}} \times \operatorname{tg} \alpha \sqrt{\frac{m_{r d} \times C_{r d}}{\left(1-\frac{\delta^{2}}{4 \pi^{2}}\right) \times\left(1+K_{c}\right)}} \\
& +\frac{1}{1+K_{c}}\left(F_{r}+2 h \times V_{x_{i}}-\operatorname{tg} \alpha \times m_{r d}\right),
\end{aligned}
$$

where $m_{r d}, C_{r d}$ - reduced mass and rigidity of the needle at lateral interaction with pitched cam; $\alpha$ - the angle of profile of working surface of cam; $F_{r}$ - resisting force to needle movement in race, which is created artificially in order to prevent its lowering in needle race; $h$ - damping coefficient; $\delta$ - logarithmic decrement of oscillation ( $h$ and $\delta$ determined by attenuation of oscillations, corresponding to impact process); $K_{c}$ - coefficient, which takes into account additional deformations of the bend of rod and heel of the needle at the moment of impact. Useful resisting force, which corresponds to the force of friction of old loop during its takedown, was neglected, because the needle did not perceive the effect of raid-in thread during the impact [25].

The difference between experimental $y_{\text {max }_{\text {exp }}}$ and analytical $y_{\text {max }_{c a l}}$ values $y_{\text {max }_{i}}$ did not exceed $8 \%$ with a tendency to decrease during the increase of loads. At any time thereafter the calculated values $y_{\text {max }_{c a l}}$ were used, which, taking that $y_{\text {max }_{c a l}}>y_{\text {max }_{e p p}}$, affected the estimated factor of safety.

Preliminary the transition from stress in the heel of the needle to stress in its hook under different load conditions was performed:

$\sigma_{i}=K \times y_{\max _{i}}$,

where $K=f\left(l_{q}\right) / A$ - the coefficient of transition from load to stress; $f\left(l_{q}\right)$ - an expression that takes into account the effect of change of the area and the form of cross-section of the needle rod from the heel to the hook [26], and the reflection of waves in the places of sharp change in the needle shape [27]; $A$ - cross-sectional area of the needle rod in the heel area.

As a result, for different levels of load it were taken $\bar{\sigma}_{i} \equiv \bar{\sigma}_{R_{d} N_{i}}=49.8 ; 54.2 ; 57.6 \mathrm{MPa}$.

Taking into account the pairs of data $\bar{\sigma}_{R_{d} N_{i}}$ and $\lg N_{i}$, the following dependency was obtained, which approximated the curve of limited fatigue of hooks of needles in the straight line within the calculated area:

$\bar{\sigma}_{R_{d} N_{i}}=-18.727 \lg \bar{N}_{i}+198.017+2.641 U$.

Obviously that for average values of limited longevity $\bar{N}_{i}$ with probability $P=0.5$ we have $U=0$. Since $\bar{\sigma}_{R_{d} N_{i}}$ is a linear function of two normally distributed stochastic values $\lg N_{i}$ and $U$, then the average quadratic deviation of its values is [23]:

$$
\begin{aligned}
& S_{\sigma_{R_{d} N_{i}}}=\sqrt{(-18.727)^{2} S_{\lg N_{i}}^{2}+2.641^{2} \times S_{U}^{2}} \\
& =\sqrt{(-18.727)^{2} 0.907^{2}+2.641^{2} \times 1^{2}}=17.19 \mathrm{MPa} .
\end{aligned}
$$

Taking that, mathematical expectations for different levels of stress $\bar{\sigma}_{R_{d} N_{i}}$ are in confidence intervals $\left\{\bar{\sigma}_{R_{d} N_{i}}+\varepsilon ; \bar{\sigma}_{R_{d} N_{i}}-\varepsilon\right\}$, where $\varepsilon=Z_{\alpha \mid 2} \frac{S_{\sigma_{R_{N} N_{i}}}}{\sqrt{n}}=3.37 \mathrm{MPa}-$ the margin of error for determination $S_{\sigma_{R_{d} N_{i}}}$ at the confidence interval $\theta=0.95$ and accepted sample size.

The parameter $m$, which characterized the angle of slope of the working surface of the direct fatigue of hooks of the needle in semi-logarithmic coordinates, was determined by the formula $m=\frac{\sigma_{R_{d} N_{2}}-\sigma_{R_{d} N_{1}}}{\lg \bar{N}_{1}-\lg \bar{N}_{2}}$ and after plugging the authors received $m=18.6$, which was within the permissible limits $m=10 \ldots 100$ [28].

Since the test testing is time consuming, its use at the design stage is limited. It is proposed to use statistical information on operating time for fatigue failure of hooks of the needles in accordance with the results of observations for knitting mechanisms in the production conditions. In accordance with operational observations, characteristics of loading (amplitude of load and corresponding number of cycles) were determined for the needles of two positions (0-1308 - with the long, and 0-1306 - with average length of heel), which had different conditions of load. The number of loads of the needles of $q$ position ( $q=1$ - for the needles $0-1308, q=2$ - for the needles $0-1306$ ) before the fatigue failure of their hooks was calculated by the formula: $N^{q}=N_{b l}^{q} \times v_{b l}^{q}$, 
where $v_{b l}^{q}=60 \frac{T_{i}^{q}}{t}-$ the number of identical units of load of the needles of $q$ position before the fatigue failure of hooks (equal to the number of piece goods, made during the average longevity $T_{i}^{q}$ of the needle of $q$ position with a steady duration of technological cycle $t$ in minutes); $N_{b l}^{q}=\sum N_{i}^{q}-$ total number of cycles of loads of the needles of $q$ position during the manufacture of piece goods, which is equal to the sum of cycles of loads $N_{i}^{q}$ of the needles of $q$ position at $i$ level of load.

The calculation $N_{b l}^{q}$ was preceded by the analysis of movement of the heel of the needle with regard to the cams of knitting systems of automatic half-hose machines at the manufacture during the production of various parts of the product, taking into account the most common trajectories of the heels of the needles in accordance with the technological requirements.

The formulas for calculation $N_{i}^{q}$ of the needles on six levels of load with the cams of knitting systems at the actual operating speed are provided in Table 1.

In Table $1 n_{s p}, n_{a n k}, n_{f t}, n_{h l}, n_{t o e}, n_{t r}$ mean the number of looped rows on the spandex, ankle, foot, pockets of the heel and toe areas, as well as on the technological rows; $\kappa$ means the number of interactions between the needle and the pitched cam (with a one-time interaction $\kappa=1$ ).

According to the results of calculations, it was received $N_{f}^{0-1306}=8.37 \times 10^{7}$ and $N_{f}^{0-1308}=4.77 \times 10^{7}$ cycles.

The actual load with the expressed regularity of the alternation of different levels during the cycle of production of piece goods was replaced by a block load, which was equivalent as to the degree of accumulation of fatigue

Table 1 The formulas for calculation the cycles of load $N_{i}^{q}$ of the needles of positions $0-1306$ and $0-1308$

\begin{tabular}{lc}
\hline & Interaction with pitched cams \\
$\begin{array}{l}\text { For raising } \\
\alpha=38.0^{\circ}\end{array}$ & $\begin{array}{c}\text { For lowering } \\
\alpha=47.5^{\circ}\end{array}$ \\
\hline $1^{\text {st }}$ mode & $4^{\text {th }}$ mode \\
$\left(V_{x}=0.6 \mathrm{~m} / \mathrm{s}\right)$ & $\left(V_{x}=0.6 \mathrm{~m} / \mathrm{s}\right)$ \\
$n_{1}^{0-1306}=4\left(n_{h l}+n_{t o e}\right)$ & $n_{4}^{0-1306}=2\left(n_{h l}+n_{t o e}+n_{t o e}\right)$ \\
$2^{\text {nd }}$ mode & $5^{\text {th }}$ mode \\
$\left(V_{x}=1.1 \mathrm{~m} / \mathrm{s}\right)$ & $\left(V_{x}=1.1 \mathrm{~m} / \mathrm{s}\right)$ \\
$n_{2}^{0-1306}=n_{2}^{0-1308}=\kappa 2 n_{s p}$ & $n_{5}^{0-1306}=n_{5}^{0-1308}=\kappa 1.33 n_{s p}$ \\
$3^{\text {rd }}$ mode & $6^{\text {th }}$ mode \\
$\left(V_{x}=1.3 \mathrm{~m} / \mathrm{s}\right)$ & $\left(V_{x}=1.3 \mathrm{~m} / \mathrm{s}\right)$ \\
$n_{3}^{0-1306}=n_{3}^{0-1308}$ & $n_{6}^{0-1306}=\kappa\left(0.91 n_{a n k}+1.12 n_{f t}+2 n_{t r}\right) ;$ \\
$=\kappa\left(n_{a n k}+n_{f t}+2 n_{t r}\right)$ & $n_{6}^{0-1308}=\kappa\left(0.91 n_{a n k}+0.68 n_{f t}+2 n_{t r}\right)$ \\
\hline
\end{tabular}

failure. In order to determine the law of distribution of loads, the dependency (Eq. (2)) was presented in the form of a polynomial, which was obtained with the use of computational experiment. The resisting force $F_{r}$ was chosen as the stochastic value; such resisting force varied widely due to the arbitrary bending of the needle rods, their lapping and lubrication rate.

The values of the upper and lower levels of each of the variables were chosen to cover the whole range of perspective designs of knitting mechanisms, in particular: $V_{x}, \mathrm{~m} / \mathrm{s}$ $(0.84 ; 1.55) ; \alpha$, degree $(34 ; 55) ; m_{r d}, \operatorname{kg} 10^{-3}(0.45 ; 0.75) ; F_{r}$, $\mathrm{N}(3.8 ; 9.0) ; C_{r d}, \mathrm{~N} / \mathrm{m} 10^{4}(1.0 ; 6.0)$. Thus, it was obtained:

$y_{\text {max }}=a_{1} \times F_{r}+a_{2} \times F_{r}^{2}+a_{3}$,

where $a_{1}=0.149-2.119 K_{c} ; a_{2}=0.055 ; a_{3}=12.55-5.164 V_{x}$ $-0.460 \alpha+4.984 \times 10^{3} m_{r d}+20.829 K_{c}-1.142 \times 10^{-4} C_{r d}$ $+4.395 \times 10^{-3} \alpha^{2}+53.88 K_{c}^{2}+0.182 V_{x} \times \alpha$ $+6.892 \times 10^{-5} V_{x} \times C_{r d}+2.521 \times 10^{-6} \alpha \times C_{r d}$.

After plugging the parameters of cams of knitting system in (Eq. (6)) we have:

1. for cams that raising the needles $\left(\alpha=38^{\circ}\right)$

$$
y_{\max }=0.382 F_{r}+0.055 F_{r}^{2}+3.062+4.166 V_{x},
$$

2. for cams that lowering the needles $\left(\alpha=47.5^{\circ}\right)$

$$
y_{\max }=0.509 F_{r}+5.47 \times 10^{-2} F_{r}^{2}+3.29+5.891 V_{x} \text {. }
$$

The resisting force $F_{r}$ under the actual operating conditions is characterized by the following parameters:

1. during the interaction with the cam that lowering the needle, we have mathematical expectation $m_{F_{r}}=6.4 \mathrm{~N}$ and mean quadratic deviation $S_{F_{r}}=0.56 \mathrm{~N}$;

2. during the interaction with the raising cam $m_{F_{r}}=7.1 \mathrm{~N}$ and $S_{F_{r}}=0.58 \mathrm{~N}$ respectively.

Equations (7) and (8) are presented in a form $y_{\max }=f\left(F_{r}, V_{x}\right)$ that is convenient during the complex analysis of dynamics and loading of needles as the components in longevity calculations. It is obviously that stochastic values $y_{\max }$ can be descripted by nonlinear equations and do not obey the normal law of distribution. This requires a special approach in determining the density of probability distribution of loads of needles $p\left(y_{\max }\right)$. In accordance with the provisions of the probability theory [29], it was obtained

$$
p\left(y_{\text {max }}\right)=p\left[q\left(y_{\text {max }}\right)\right] \times\left|q^{\prime}\left(y_{\text {max }}\right)\right|,
$$

where $q\left(y_{\max }\right), q^{\prime}\left(y_{\max }\right)$ is a function that is inverse of a function $y_{\max }=f\left(F_{o}\right)$ and its derivative. 
Taking into account the Eq. (6), we have:

$\left\{\begin{array}{l}q\left(y_{\max }\right)=-0.5 a_{1} a_{2}^{-1} \pm a_{2}^{-0.5} \times A ; \\ q^{\prime}\left(y_{\max }\right)=\left(2 a_{2}^{0.5} \times A\right)^{-1}\end{array}\right.$

where $A=\left(0.25 a_{1}^{2} a_{2}^{-1}-\left(a_{3}-y_{\max }\right)\right)^{0.5}$.

Plugging Eq. (10) in Eq. (9), we have:

$$
\begin{aligned}
& p\left(y_{\max }\right)=\frac{1}{\sqrt{2 \pi} S_{F_{r}}}\left(2 a_{2}^{0.5} \times A\right)^{-1} \\
& \times \exp \left\{-\frac{\left(-0.5 a_{1} a_{2}^{-1}+a_{2}^{-0.5} \times A-m_{F_{r}}\right)}{2 S_{F_{r}}^{2}}\right\} .
\end{aligned}
$$

The expression (Eq. (11)) makes it possible to construct histograms $p\left(y_{\max }\right)$ of relative frequency for the appearance of the values of the needle load for six variants according to Table 1, and to use such histograms for compilation of cyclogram of loading of the needle. The sequence of the histogram construction (step diagram 2, presented in Fig. 1) is presented for one of the modes of needles load, namely $2^{\text {nd }}$ mode at $\alpha=38^{\circ}$ and $V_{x}=1.1 \mathrm{~m} / \mathrm{c}$. In order to construct the polygon (curve 1) of probability frequency $y_{\max }$, the following dependencies were taken into account: $p\left(y_{\max }\right)>0$, if $\forall 0.25 a_{1}^{2} a_{2}^{-1}+y_{\max } \geq A$; $p\left(y_{\max }\right)=0$, if $\forall 0.25 a_{1}^{2} a_{2}^{-1}+y_{\max }<A$.

Next, the limits of load values $y \in\left[y_{\min } ; y_{\max }\right]$, which had been calculated using Eq. (7), were split into $l$ equal intervals (in Fig. $1 l=8$ ), and using Eq. (11), the corresponding values of the function $p\left(y_{k}\right)$ were calculated at the limits of each interval. The probability $P_{i}$ of reaching the loading amplitude $y_{i}$ at a certain interval $y_{i} \in\left[y_{l}-0.5 \Delta y_{k} ; y_{l}+0.5 \Delta y_{k}\right]$, where $y_{l}$ was the value of load in the middle of the interval with the length $\Delta y_{k}=\left(y_{k_{\max }}-y_{k_{\min }}\right) / l$, was determined by the graphical

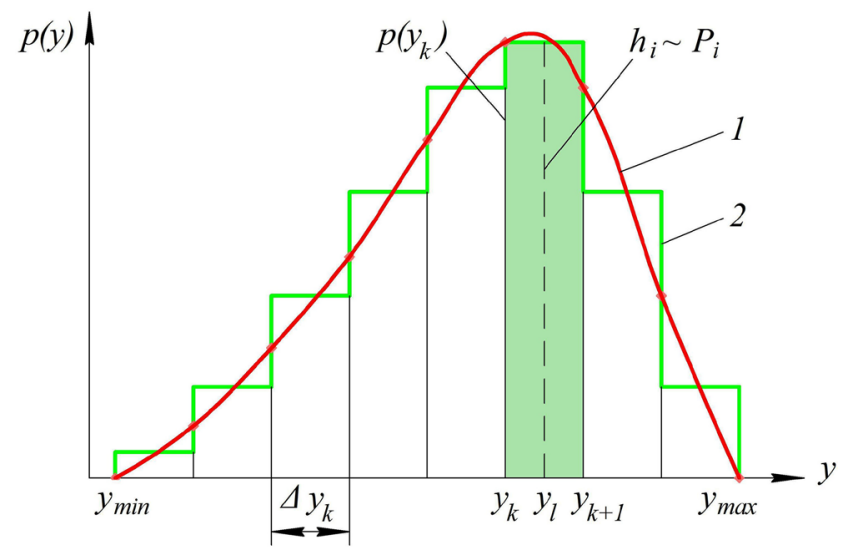

Fig. 1 Distribution of probabilities of the appearance of values of load $p(y)$ of the needle: curve 1 - the polygon of probability frequency $y$; step diagram 2 - the histogram of loads method [29]. The heights $h_{i}$ that were under the curve of distribution $p(y)$ on the interval from $y_{k}$ to $y_{k+1}$, were proportional to the probabilities $P_{i}$.

Similarly, the histograms for all modes of load of the needles at different combinations of values $V_{x}$ and $\alpha$ were obtained in order to construct generalizing cyclogram of loading of needles before failure (a step-by-step diagram with $j \times i$ degrees of change $y$, where $j$ was the mode of load according to Table 1 , and $i$ was the interval in $j$ mode). The number of cycles of load $N_{j i}$ with the amplitudes $y_{i}$, that fell into the $i$ interval during the $j$ mode was determined by the formula $N_{j i}=P_{i} \times N_{j}$, where $N_{j}$ was the cycle longevity of hook of the needle to the fatigue destruction during the $j$ mode of load. It was also considered that $\sum_{i=1}^{S} P_{i}=1$.

In the transition to the cyclogram $\left\{\sigma_{j i} ; N_{j i}\right\}$, Eq. (3) was used. Obviously, the total number of cycles of needle load before the failure $N_{f}$ could be calculated as $N_{f}=N_{\Sigma}=\sum N_{j i}$.

Equivalent stress $\sigma_{\text {equiv }}$, which was the limited fatigue of hooks of the needle $\sigma_{R_{d} N}$ considering the number of load cycles $N_{f}$, was determined by the formula:

$\sigma_{\text {equiv }}=\sigma_{\max m} \sqrt{\sum\left[\frac{N_{j i}}{\sum N_{j i}}\left(\frac{\sigma_{j i}}{\sigma_{\max }}\right)^{m}\right]}$,

where $\sigma_{\max }$ was the maximum value in the spectrum of the true stress.

As a result, the following characteristics of resisting force of fatigue of hooks of the needles 0-1306 and 0-1308 were obtained:

$\sigma_{R_{d} N_{f}}^{0-1308}=52.06 \mathrm{MPa}$ at $N_{f}^{0-1308}=4.77 \times 10^{7}$ cycles

$\left(\lg N_{f}^{0-1308}=7.68\right)-$ point $A$ in Fig. 2;

$\sigma_{R_{d} N_{f}}^{0-1306}=47.95 \mathrm{MPa}$ at $N_{f}^{0-1306}=8.37 \times 10^{7}$ cycles

$\left(\lg N_{f}^{0-1306}=7.92\right)-$ point $B$ in Fig. 2.

Let's compare the values of limited fatigue $\bar{\sigma}_{R_{d} N_{i}}$ of hooks of the needles, obtained in view of the results of test testing and operational observations $\sigma_{R_{d} N_{f}}^{q}$. Using the equation of regression (Eq. (4)) at $P=0.5$ and $U=0$ for fixed values of cycle longevity to fatigue failure of the hook $\lg N_{f i}^{q}$, we have:

$\bar{\sigma}_{R_{d} N_{i}}=54.2 \mathrm{MPa}$ at $N_{2}^{0-1308}=4.77 \times 10^{7}$ cycles

$\left(\lg N_{2}^{0-1308}=7.68\right)-$ point $C$ in Fig. 2;

$\bar{\sigma}_{R_{d} N_{i}}=49.6 \mathrm{MPa}$ at $N_{1}^{0-1306}=8.37 \times 10^{7}$ cycles

$\left(\lg N_{1}^{0-1306}=7.92\right)-$ point $D$ in Fig. 2. 


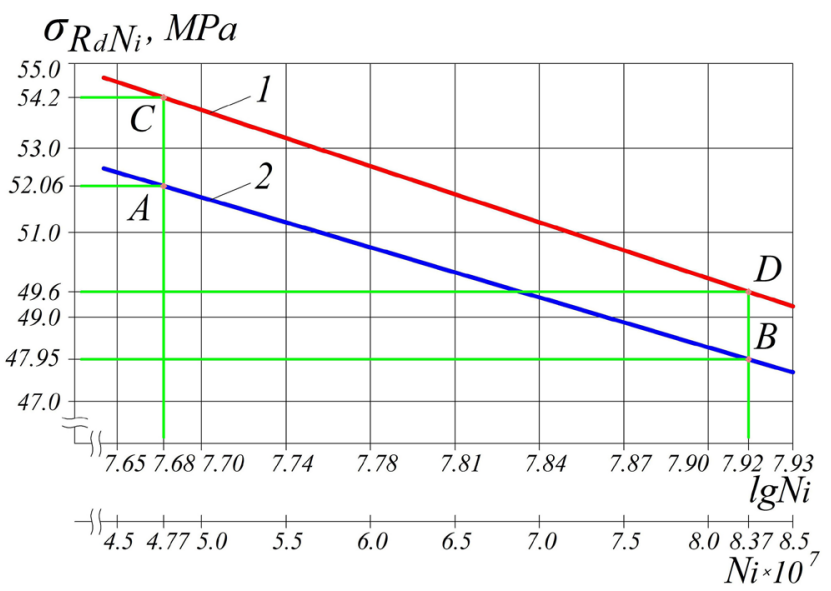

Fig. 2 Dependences of the limits of limited fatigue of the needle $C_{r d}$ on its cycle longevity $N_{i}: 1$ - according to the results of test testing; 2 - according to the results of operational observations

The corresponding values according to the results of observations are 47.95 $\mathrm{MPa}$ and 52.06 $\mathrm{MPa}$, which means that the variation of results of tests for fatigue falls within the interval $\Delta \sigma_{R_{d} N_{i}} \leq 3.37 \mathrm{MPa}$ that is within the limits of confidence intervals. Consequently, with the accuracy that is enough for design, it is possible to use a diagram $\sigma_{R_{d} N}=f(\lg \bar{N})$, which is constructed based on the results of operational observations during the production, in the calculations.

Obviously that the condition for fatigue longevity of the needles for the number of load cycles $N_{\Sigma}$, which corresponds to the given longevity $T$ in hours, is considered to be fulfilled if

$$
K_{\sigma}=\frac{\sigma_{R_{d} N_{i}}}{\sigma_{\text {equiv }}} \geq\left[K_{\sigma}\right]
$$

In order to calculate the quantile of the normal distribution, we take into account that $u_{p}=\frac{\lg \left(\sigma_{R_{d} N_{i}} / \sigma_{\text {equiv }}\right)}{\sigma_{\lg N_{i}}}$, as well as the expression for calculation of probabilistic statement of coefficient of the factor of safety $K_{\sigma}=10^{U_{p} \times \sigma_{\lg N}}$, where $\sigma_{\lg N}$ is a mean quadratic deviation of logarithm of longevity in cycles of load.

Taking into account the prospects for intensification of technological processes, first of all due to the increase of speed, it is rational to predict in the calculations for advanced models of automatic half-hose machines possible rebounds of the needles from the pitched cams and their interaction with restrictive lateral cams, which causes additional cycles of load of the needles.

In [30] the condition for rebound of needles is presented, and the corresponding circular speeds of needle cylinder are set:
$V_{x} \geq F_{r} / \operatorname{tg} \alpha\left(\sqrt{m_{r d} \times C_{r d} \times K_{c} /\left(1-\delta^{2} / 4 \pi^{2}\right)}-2 h \times m_{r d}\right)$.

Calculated by the expression Eq. (14), the circle speeds $V_{x} \geq 1.64 \mathrm{~m} / \mathrm{s}$ are critical to the rebound. In the presence of rebound of the needles, the number of cycles of load of the needle redouble $(\kappa=2)$ in the formulas in Table 1 .

The restrictive lateral cams are designed to restrict the movement of separate needles outside the lower edges of pitched cams in their inertial running. It is found that the impact of the needle on a restrictive cam is impossible due to its inhibition by the force $F_{r}$ under the condition

$$
V_{x_{\max }} \leq \sqrt{2[\Delta] \times F_{r} / m_{r d}} \operatorname{ctg} \alpha,
$$

where $\Delta$ is the value of the clearance between the lower end of the needle and the working surface of the restricting cam. The value of the clearance, which prevents the impact, is $\Delta=m_{r d}\left(V_{r e b}\right)^{2} / 2 F_{r} \leq[\Delta] \times 10^{-3} \mathrm{~mm}$.

The vertical component of speed of the needle during the rebound $V_{r e b}$ at the moment of its impact with pitched cam is determined by the formula:

$$
\begin{aligned}
& V_{r e b}=V_{s t} \times\left(1+\left|\sqrt{1-\left(\frac{F_{r}+2 m_{r d} h V_{s t}}{V_{s t} \times C_{r d} \times K_{c}}\right)^{2}}\right|\right) \\
& -\frac{h}{K_{c} \times C_{r d}}\left(F_{r}+2 h V_{s t} \times m_{r d}\right),
\end{aligned}
$$

where $V_{s t}=V_{x} \operatorname{tg} \alpha$ is the speed of the needle with steady motion along the cam. It is obviously that $V_{r e b} \geq V_{s t}$.

In case of interaction of the needle with a limiting cam, the impact load is calculated as

$$
y_{\max }=V_{r e b} \sqrt{m_{r d} \times C_{r d}^{\prime} /\left(1-\delta^{2} / 4 \pi^{2}\right)}-F_{r},
$$

where $C_{r d}^{\prime}$ is the reduced longitudinal and bending rigidities of the needle during the straight vertical impact with a limiting cam.

The main directions for the improvement of cams of knitting systems at the minimization $y_{\text {max }}$ are analyzed by the Eqs. (2) or (6). Since the speed modes $V_{x}=\left\{V_{1}, V_{2}, \ldots V_{n}\right\}$ are set by the operating conditions, and the resisting force $F_{r}$ is regulated, the angles of cams $\alpha$ and reduced rigidity $C_{r d}$ or $C_{r d}^{\prime}$ at a constant design of the needles are the parameters of the impact on the value $y_{\max }$.

The most common constructive solutions for reduction of $y_{\max }$ are provided in [16], where the advantages and disadvantages of different designs of cams are presented, as well as pointed out at the process of manufacturing and at the functional reliability of the cams.

In order to analyze the influence of constructive measures, aimed to increase the cycle longevity of needles $N_{i}$, 
it is convenient to use diagrams $\lg \bar{N}_{i}\left(\alpha, C_{r d}\right)$, presented in Fig. 3, and $\lg \bar{N}_{i}\left(\alpha, V_{x}\right)$, presented in Fig. 4.

In Fig. 3 at $\alpha=38^{\circ}, C_{r d}=5.31 \times 10^{4} \mathrm{~N} / \mathrm{m}$ and $V_{x_{i}}=1.2 \mathrm{~m} / \mathrm{s}$ we have $\lg \bar{N}_{i}=7.83$ or $\bar{N}_{i}=6.76 \cdot 10^{7}$ cycles of load; in Fig. 4 at $\alpha=45^{\circ}, V_{x_{i}}=1.2 \mathrm{~m} / \mathrm{s}$ and $C_{r d}=5.31 \times 10^{4} \mathrm{~N} / \mathrm{m}$ we have $\lg \bar{N}_{i}=7.50$ or $\bar{N}_{i}=3.17 \times 10^{7}$ cycles of load. Diagrams in Fig. 3 and Fig. 4 are expedient to use both in the design and in the checking calculations.

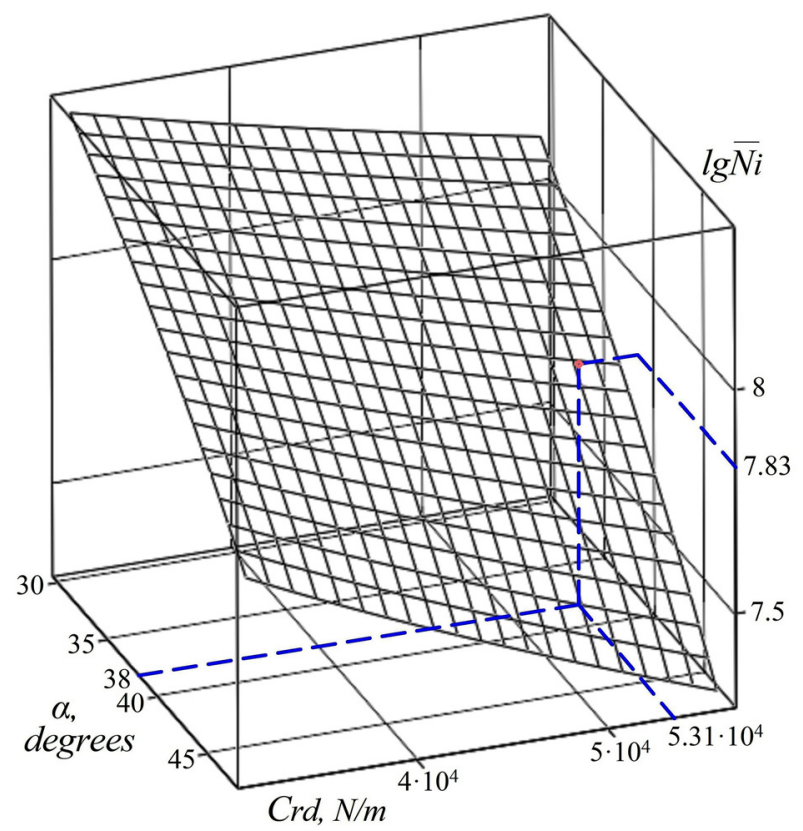

Fig. 3 Dependences of cycle longevity of the needle $N_{i}\left(\lg \bar{N}_{i}\right)$ on the angle of cam $\alpha$ and on the reduced rigidity $C_{r d}$ (at $V_{x_{i}}=1.2 \mathrm{~m} / \mathrm{s}$ )

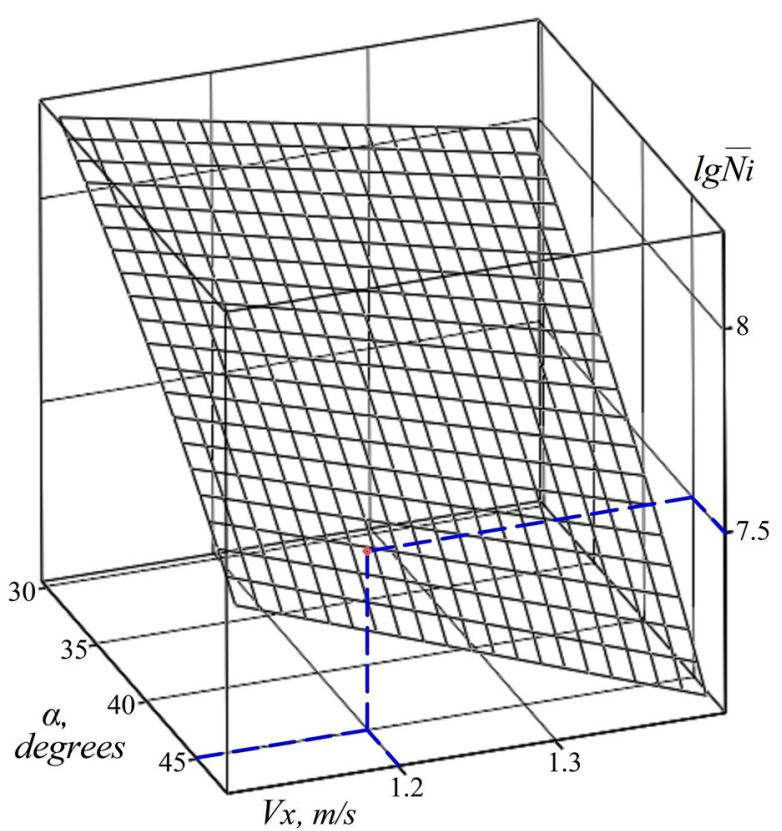

Fig. 4 Dependences of cycle longevity of the needle $N_{i}\left(\lg \bar{N}_{i}\right)$ on the angle of cam $\alpha$ and on the circular speed of the cylinder $V_{x_{i}}$ (at $C_{r d}=5.31 \times 10^{4} \mathrm{~N} / \mathrm{m}$ )

\section{Results}

A unified system of calculation of loads, loadings, fatigue longevity and endurance strength of rod elements of complex form on the example of knitting needles is developed. The general description of density of distribution of amplitude of loads that do not obey the normal law of distribution is presented, the cyclograms of loading are constructed, and the characteristics of loading of the needles are calculated. The results of forceful analysis in a uniform form of a polynomial, as well as statistical data on the resource of rod elements to fatigue destruction, have been used.

According to the results of calculations, the numbers of loads before the fatigue failure of the needle hooks of different positions $N_{f}^{0-1306}=8.37 \times 10^{7}$ and $N_{f}^{0-1308}=4.77 \times 10^{7}$ of cycles were obtained. According to the results of the bench tests, the corresponding values of limit values of limited fatigue of the needle hooks are $\bar{\sigma}_{R_{d} N_{i}}=49.6 \mathrm{MPa}$ and $\bar{\sigma}_{R_{d} N_{i}}=54.2 \mathrm{MPa}$.

In order to improve the accuracy of calculations of loadings of the needles, the analysis of the conditions for a possible rebound of the needle from the pitched cam and its interaction with the restrictive lateral cam is performed. It is found that in calculations of loading of the needles at the circle speeds of the cylinder up to $V_{x}=1.64 \mathrm{~m} / \mathrm{s}$ the occurrence of repeated impacts is impossible; and at $V_{x} \leq 1.71 \mathrm{~m} / \mathrm{s}$ it occurs an interaction with restrictive lateral cam.

The dependence of the limited longevity of the needle on the cycles of load to fatigue failure is described. The Eq. (4) and (or) the diagram in Fig. 2 contribute to the implementation of both direct checking calculations of longevity and inverted ones, which are used to determine the conditions of load with given operating time to failure.

Generalized dependences in Fig. 3 and Fig. 4 are proposed for operational analysis of the influence of constructive means, aimed to reduce the loading of the needles.

\section{Conclusions}

The results of the study make it possible to evaluate the effectiveness of constructive and technological solutions at the design stage quickly, and to select the best solution among the possible ones to provide given fatigue longevity of the needles with their constant design.

The relevance of the article is confirmed by the current tendency in industrial production or modernization of comparatively small number of equipment, which requires a reduction in cost and duration of design and production of pilot equipment, primarily due to the calculated recommendations. 
In order to implement the calculations, it is necessary to accumulate a sufficient database of failures of the needles in production, which will increase the accuracy of the adopted recommendations.

Thereafter, the authors plan to work on calculations for the rod elements, to estimate their fatigue longevity in the probabilistic statement, considering the variation of loads and strength characteristics of the material of the needles, which in turn will increase the accuracy of prediction of the longevity of the needles and analysis of their residual life in production. The latter will contribute to the

\section{References}

[1] Astaraki, S. "Reliability-based fracture analysis with uncertainty on material degradation", International Journal of Structural Integrity, 7(4), pp. 571-583, 2016. https://doi.org/10.1108/IJSI-07-2015-0022

[2] Krasovskii, A. Y., Kramarenko, I. V., Gaidamaka, V. G. "Character and causes of in-service needle failure in knitting machines", Strength of Materials, 15(7), pp. 969-972, 1983.

https://doi.org/10.1007/bf01528942

[3] Ilia, V., Mangey, R. "Reliability Engineering: Theory and Applications", CRC Press, Boca Raton, FL, USA, 2018. https://doi.org/10.1201/9781351130363

[4] Antsupov, A. V., Antsupov, A. V., Antsupov, V. Р. "Теория и практика обеспечения надежности деталей машин по критериям кинетической прочности и износостойкости материалов" (Theory and Practice of Assurance of Machine Element Reliability according to Criteria of Material Kinetic Strength and Wear Resistance), G. I. Nosov Magnitogorsk State Technical University Publisher, Magnitogorsk, Russia, 2015. [online] Available at: https://www.elibrary.ru/item. asp?id=23426805 [Accessed: 28 December 2020] (in Russian)

[5] Aven, T. "Improving the foundation and practice of reliability engineering", Proceedings of the Institution of Mechanical Engineers, Part O: Journal of Risk and Reliability, 231(3), pp. 295-305, 2017. https://doi.org/10.1177/1748006X17699478

[6] Boukharouba, T., Elboujdaini, M., Pluvinage, G. (eds.) "Damage and Fracture Mechanics: Failure Analysis of Engineering Materials and Structures", Springer, Dordrecht, Netherlands, 2009. https://doi.org/10.1007/978-90-481-2669-9

[7] Troshchenko, V. T., Khamaza, L. А. "Механика рассеянного усталостного повреждения металлов и сплавов" (Mechanics of diffuse fatigue damage of metals and alloys), G. S. Pisarenko Institute for Problems of Strength, National Academy of Sciences of Ukraine, Kyiv, Ukraine, 2016. [online] Available at: http://www. nas.gov.ua/EN/Book/Pages/default.aspx?BookID=0000008999 [Accessed: 28 December 2020] (in Russian)

[8] Ibrahim, R. A. "Overview of Structural Life Assessment and Reliability, Part V: Joints and Weldments", Journal of Ship Production and Design, 32(01), pp. 1-20, 2016.

https://doi.org/10.5957/jspd.2016.32.1.1 development of a strategy of rational planning of automatic half-hose machines maintenance.

\section{Acknowledgement}

All presented materials were obtained as a result of collaboration of the scientists of the Kyiv National University of Technologies and Design, Ukraine during the research work on the scientific direction "The Improvement of Technological Equipment and Applied Mechanical and Technological Systems".

[9] Alshoaibi, A. M., Ghazwani, M. A., Hakami, M. H. "Fatigue life and reliability assessment of metal structures", Engineering Solid Mechanics, 9(1), pp. 13-22, 2021. https://doi.org/10.5267/j.esm.2020.7.001

[10] Basu, M., Manolache, V. "The research of knitting process and the needle failures", Metalurgia International, 15(4), pp. 32-34, 2010.

[11] Reza, M. H., Hossain, M. K. "A Study on Causes of Knitting Machine Stoppages and Their Impact on Fabric Production", European Scientific Journal, 11(33), pp. 262-269, 2015. [online] Available at: https://eujournal.org/index.php/esj/article/view/6650 [Accessed: 28 December 2020]

[12] Duru, S. C., Candan, C., Mugan, A. "Evaluation of wear in needles working with open end cotton yarn", Tekstil ve Konfeksiyon, 25(2), pp. 160-165, 2015.

[13] Zhang, Z., Bai, S., Xu, G., Liu, X., Wang, F., Jia, J., Feng, Z. "Research on the knitting needle detection system of a hosiery machine based on machine vision", Textile Research Journal, 90(15-16), pp. 1730-1740, 2020. https://doi.org/10.1177/0040517519899173

[14] Saggiomo, M., Klug, J., Cloy, Y. S., Gries, T. "Automatic removal of faulty weft yams: Increase of reliability through machine vision system", Melliand International, 23(3), pp. 149-151, 2017.

[15] Berezin, L. M. "Оцінка довговічності та надійності в’язальних механізмів панчішно-шкарпеткових автоматів" (Assessment of longevity and reliability of knitting mechanisms of automatic halfhose machines), KNUTD, Kyiv, Ukraine, 2013. (in Ukrainian)

[16] Pipa, B. F., Pleshko, S. А. "Удосконалення робочих органів механізмів в'язання клуглов'язальних машин" (Improvement of working bodies of mechanisms of knitting circular knitting machines), KNUTD, Kyiv, Ukraine, 2012. (in Ukrainian)

[17] Zhao, C., Song, G. L., Xu, L. "Optimal Design of Computerized Flat Knitting Machine Cam Curves Based on UG and ANSYS/LS-DYNA", Applied Mechanics and Materials, 529, pp. 410-414, 2014.

https://oi.org/10.4028/www.scientific.net/AMM.529.410

[18] Research Cosmos "A Global Library of Market Research Reports", [online] Available at: https://www.researchcosmos.com/ [Accessed: 29 December 2020] 
[19] Groz-Beckert "Review: ITMA Barcelona 2019", [online] Available at: https://www.groz-beckert.com/en/company/news/trade-fair-review-itma-2019.html [Accessed: 29 December 2020]

[20] Duru, S. C., Candan, C., Mugan, A. "Effect of yarn, machine and knitting process parameters on the dynamics of the circular knitting needle", Textile Research Journal, 85(6), pp. 568-589, 2015. https://doi.org/10.1177/0040517514547216

[21] Fouda, A., El-Hadidy, A., El-Deeb, A. "Knitting Force Measurement on Flat Knitting Machines", Journal of Textiles, 2014, Article ID: 546472, 2014.

https://doi.org/10.1155/2014/546472

[22] Wray, G. R., Burns, N. D. "20-Dynamic Forces in Weft-Knitting: Part I: A Comparison of Measured Non-knitting Cam Forces with Mathematically Predicted Values", The Journal of The Textile Institute, 67(5), pp. 149-155, 1976.

https://doi.org/10.1080/00405007608630558

[23] Sosnovskyi, L. А. "Об оценке долговечности при циклических нагружениях" (On the estimation of longevity under the cyclic loads), The Problems of Strength, 11, pp. 16-21, 1986. (in Russian)

[24] Yudin, Y. V., Maysuradze, M. V., Vodolazskiy, F. V. "Организация и математическое планирование эксперимента" (Organization and mathematical planning of the experiment), Publishing House of the Ural University, Yekaterinburg, Russia, 2018. [online] Available at: http://hdl.handle.net/10995/65224 [Accessed: 29 December 2020] (in Russian)

[25] Shen, Y., Yu, C., Yang, J. "A study on fiber motion in the drafting zone and hook removal", Textile Research Journal, 90(11-12), pp. 1277-1290, 2020.

https://doi.org/10.1177/0040517519889557
[26] Garbaruk, V. N. "Проектирование трикотажных машин" (Designing of knitting machines), Mashinostroenie, Leningrad, Russia, 1980. (in Russian)

[27] Pipa, B. F., Golovchan, V. T., Gaidaychuk, I. Р. "О распространении волн напряжений в штампованной игле трикотажных машин" (On propagation of stress waves in a stamped needle of knitting machines), News of Higher Educational Institutions. Light Industry Technology, 2, pp. 147-153, 1975. (in Russian)

[28] Kogaev, V. Р. "Расчеты на прочность при напряжениях, переменных во времени" (Strength calculations at stresses that are variable in time), Mashinostroenie, Moscow, Russia, 1993. [online] Available at: https:/ur.b-ok.lat/book/5588020/2f1397 [Accessed: 29 December 2020] (in Russian)

[29] Rumshynskyi, L. Z. "Элементы теории вероятностей" (Elements of theory of probability), Nauka, Moscow, Russia, 1976. (in Russian)

[30] Berezin, L. M. "До розрахунку довговічності в’язальних голок шкарпеткових автоматів за критерієм втомленісної міцності" (To the calculation of longevity of the knitting needles of automatic half-hose machines by the fatigue strength criterion), Bulletin of the Kyiv National University of Technologies and Design, 58(2), pp. 116-120, 2011. [online] Available at: https://er.knutd. edu.ua/handle/123456789/3935 [Accessed: 29 December 2020] (in Ukrainian) 